\title{
Interaction Design of Public Electronics Equipment: Approach to Categorization Systems and Analysis Model
}

\author{
Barreto Fernandes, Francisco Antonio ${ }^{a}$ \& Hernandis-Ortuño, Bernabéb \\ a Associated Professor. Instituto Politécnico de Leiria, Portugal. francisco.fernandes@gmail.com \\ ${ }^{b}$ Full Professor. Universitat Politècnica de València. Spain. bhernand@upv.es
}

\begin{abstract}
Resumo
O desenvolvimento tecnológico alterou a forma como os utilizadores se relacionam com os produtos - deixaram de ser recetores passivos de funções para interagirem com sistemas cada vez mais complexos. A presente pesquisa aborda a problemática da interação do consumidor com produtos tecnológicos eletrónicos públicos. São vários os estudos que se debruçam sobre as disciplinas que estudam a interação entre o utilizador e o produto eletrónico (Preece, 2005; Johnson-Laird, 1983; Helander, 1997, Sutcliffe, 1995; Norman, 1990; Moraes, 2001), possibilitando obter conhecimentos sobre o ser humano, a tecnologia e sobre a maneira como atuam. Esta pesquisa pretende-se identificar os domínios do design de interação que envolvem o sistema homem-máquina, designadamente as disciplinas que concorrem para uma boa usabilidade. É proposto seis tipologias que descrevem caraterísticas de interface específicas estudadas segundo o modelo de complexidade definido por Gomes Filho (2003). Realizou-se uma pesquisa exploratória em Portugal a qual identificou vinte e seis sistemas interativos. Para caraterizar os sistemas eletrónicos públicos, o estudo apresenta uma analise estruturada das variáveis atrás referidas, tanto em relação a sua confiabilidade e validade, como também, à sua funcionalidade. Os resultados são comparados com a literatura e são discutidas as suas implicações para o desenho do Modelo de Articulação Utilizador - Sistema.
\end{abstract}

Palavras chiave: Design, Interação, Sistemas, Usabilidade, Modelo de Análise.

\footnotetext{
Abstract

Technological development has changed the way users relate to products, they are no longer passive receivers of functions to interact with increasingly complex systems. This research addresses the problem of consumer interaction with public electronic technology products.

There are several studies dealing with the disciplines that study the interaction between the user and the electronic product (Preece, 2005; Johnson-Laird, 1983; Helander, 1997, Sutcliffe, 1995; Norman, 1990; Moraes, 2001), making it possible to obtain knowledge about human beings, technology and the way they operate.
} 
This research aims to identify the areas of interaction design that involve the humanmachine system, in particular the disciplines that contribute to good usability.

Six typologies are proposed that describe specific interface characteristics studied according to the model of complexity defined by Gomes Filho (2003).

Exploratory research in Portugal identified twenty-six interactive systems. To characterize the public electronic systems, the study presents a structured analysis of the variables mentioned previously, in relation to both reliability and validity, as well as functionality.

The results are compared with the literature and the implications discussed for the design of the User Interface System Model.

Keywords: Interaction Design, Categorization Systems, Usability, Analysis Model, Public Equipment.

\section{Introdução}

O presente estudo, pretende contribuir para um melhor entendimento da problemática da interação homem - sistema, e permitir que a usabilidade seja levada em consideração pelos designers deste tipo de equipamentos, designadamente, no desenvolvimento de conceitos de interação nos produtos.

Para tal, pretende-se compreender a funcionalidade exigida e as restrições sobre as quais um produto deve operar ou ser desenvolvido, por forma a passar essa informação para as atividades de design. Também será pertinente: identificar as caraterísticas dos sistemas interativos públicos e determinar tipologias segundo a funcionalidade e analisar o grau de complexidade; compreender os fatores humanos que intervêm na interação utilizador-sistema; identificar os pressupostos de usabilidade que poderão ser passados para a atividade de design; explicar os princípios do design de interação; compreender as necessidades dos utilizadores, as suas capacidades e os seus objetivos.

Este estudo baseou-se numa estratégia qualitativa de pesquisa, de caráter exploratório, por meio do levantamento e análise de fontes secundárias (bibliográficas e documental) e pela observação direta dos sistemas no contexto geográfico de Portugal. A metodologia utilizada no estudo considerou ainda um levantamento teórico sobre o processo de interação utilizador - sistema e as suas variáveis e a usabilidade. Para isso, foi utilizada uma abordagem indutiva, onde se tentou unir as proposições particulares observadas e analisadas, por forma, a apresentar um modelo de análise.

\section{Design de Equipamentos Públicos Eletrónicos}

\subsection{Equipamentos Públicos Eletrónicos}

No Design, um dos principais aspetos ligados ao uso do produto pode ser entendido a partir do estudo na relação que se estabelece entre o Homem - Máquina. Ao designer é dada a responsabilidade de conceber a forma como esta ligação é estabelecida. 
Desde a Revolução Industrial que a produção em massa permitiu ao homem entrar em contacto com um número crescente de objetos, com diferentes funções, materiais, formas e modos de operar.

Por um lado, a disseminação de novos objetos possibilitou um maior conforto para o utilizador, por outro, aumentou-lhe as dificuldades de se relacionar com eles. Esta dificuldade é sentida com mais intensidade durante as primeiras utilizações, podendo causar nele a sensação de surpresa, confusão, dificuldade, erro e frustração.

Atualmente, os objetos estão mais tecnológicos, complexos e difíceis de utilizar, quer através da adição de novas funções quer pela redução do tamanho.

Segundo Norman (1990), sempre que o número de funções e de operações necessárias é maior que o número de comandos, o design converte-se em arbitrário, antinatural e complicado. A mesma tecnologia que simplifica a vida ao adicionar mais funções a cada objeto, também a complica fazendo com que cada artefacto seja mais difícil de aprender e de utilizar.

No espaço público, o utilizador vive rodeado de novos equipamentos eletrónicos urbanos altamente tecnológicos (máquinas ATM, de bilhética, de controle de acessos, validadores de títulos de transporte, de venda de alimentos, controles de elevadores, entre outros). Parte destes equipamentos apresenta um elevado número de funções, reduzida interatividade e lógicas diferentes de operar, obrigando a que o utilizador altere de modelo mental durante as diferentes interações com os diferentes dispositivos com que se confronta.

\subsection{Design de Interação}

Muitas das questões que se levantam ao Design de Interação estão ainda por revolver. Segundo Preece (2005), o Design de Interação tem como objetivo desenvolver objetos/produtos interativos que apoiem as pessoas no seu dia-a-dia. Por outro lado, usabilidade refere-se à fácil aprendizagem, a uma efetiva utilização, a proporcionar uma agradável experiência e ao envolvimento dos utilizadores no processo de design.

O objetivo do Design de Interação é pois, facilitar as interações entre os seres humanos com os produtos. Segundo Saffer (2006), este tipo de design deve facilitar a forma como as pessoas interagem entre si através de produtos e serviços. Num certo sentido, é também a forma como os humanos interagem com determinados produtos inteligentes que facilitam a comunicação humana.

Por outro lado, a sua aplicação visa a melhoria da relação homem-máquina (computador) já que o sucesso de um produto no mercado depende muito da experiência interativa que este pode proporcionar.

Alguns dos seus benefícios podem definir-se como:

- Adequar respostas do sistema às entradas do utilizador;

- Equilibrar a relação interação e funcionalidade;

- Prevenir erros do utilizador.

A Interação Homem - Computador é crescente e inevitável, pois grande parte da mudança da sociedade moderna assenta no seu uso. Esta não se limita à interação do utilizador com aplicações informáticas e interfaces gráficas de páginas Web. O computador apresenta-se na maior parte dos equipamentos utilizados mas é impercetível para os utilizadores. Estes não o reconhecem como tal, pois os comandos utilizados não são o rato ou teclado, mas comandos visuais, tácteis, vocais, gestuais ou de presença. 
A questão sobre a usabilidade de equipamentos eletrónicos urbanos é pouco difundida, fazendo com que seja necessária uma maior abordagem sobre o assunto. Esta questão torna-se ainda mais premente, pois estes equipamentos estão em plena expansão. No entanto esta utilização nem sempre satisfaz o utilizador, causando nele experiências negativas que na maioria das vezes, estão relacionadas com falhas de usabilidade.

\subsection{Grau de Complexidade dos Produtos}

Segundo Gomes Filho (2003), os produtos podem caracterizar-se de baixa, média e alta complexidade. Produtos de baixa complexidade são aqueles que se configuram numa só peça ou que possuem reduzido número de componentes, os de média complexidade são os que apresentam uma certo carácter sistémico e uma maior quantidade de componentes e os de alta complexidade apresentam um alto grau de sistematização.

$\mathrm{Na}$ relação do utilizador com o produto eletrónico, o interface tem caraterísticas de particular complexidade. Por um lado, o manuseamento diz respeito à operacionalidade com o objeto e aos atos físicos que se relacionam com a ação. Por outro, está implicitamente associado ao ato de controlo.

Segundo o mesmo autor, podemos ainda dividir o manuseamento dos produtos em duas categorias: simples e médio e mais complexo. O primeiro envolve uma quantidade menor de atos operacionais (ex. ligar dispositivo, pressionar um botão, digitar um número). O mais complexo necessita de maior número e variedade de ações, com maior frequência, maior velocidade, maior tempo, maior concentração mental ou psicológica.

Assim, os produtos de alta complexidade, por utilizarem um elevado grau de sistematização, apresentam normalmente na sua configuração um grande número de componentes.

Neste tipo de produtos, o sistema homem-máquina-ambiente configura-se de modo completo por meio de relações ergonómicas que se estabelecem mutuamente. $\mathrm{O}$ manuseio destes equipamentos necessita de um número de ações precisas, sequenciais, com certa velocidade, exigindo mais tempo e concentração por parte do utilizador. Exemplos deste tipo de produtos são as caixas eletrónicas, sistemas bancários e de bilhética.

Quanto aos produtos de média complexidade são os que apresentam um certo carácter sistémico, possuem uma maior quantidade de componentes e de partes que o configuram e um maior grau de tecnologia envolvida. O seu manuseamento necessita de menor quantidade de atos operacionais.

Designam-se por interfaces de uso simples, aquelas em que as tarefas não exigem dos utilizadores grandes dificuldades de aprendizagem, destreza e experiência, assim como solicita um reduzido esforço físico e mental.

Nestes produtos, o manuseamento necessita de uma quantidade reduzida de ações. No entanto, a linguagem utilizada deve ser simples e clara de forma a proporcionar facilidade, lógica e total compreensão. Exemplos deste tipo de produtos são os videoporteiros, campainhas ou comandos de elevadores.

\section{Sistemas Interactivos Públicos}

\subsection{Sistemas Interactivos Públicos - Tipologías}

Do levantamento realizado, na literatura sobre sistemas eletrónicos interativos e ilustrado com imagens recolhidas através da observação direta e pesquisa exploratória online, foram identificados um total de 
trinta e dois sistemas (32) públicos diferentes, os quais foram agrupados em seis (6) tipologias funcionais diferentes. Através da análise das caraterísticas de cada conjunto foram definidas as seguintes designações: Venda, Informação, Acessos, Bilhética Bancários, Pagamento. Na tabela 1 poderemos ver o resultado do levantamento realizado, isto é, observar quais as áreas, tipologias e produtos associados a cada grupo.

Porém, cada sistema é constituído por um posto, onde se realiza a interação e onde se executa uma ou mais tarefas, com um ou mais objetivos. Designa-se por posto, o lugar onde alguém é colocado para cumprir uma tarefa ou uma função definida, fazendo parte de um conjunto de ações determinado em si mesmo. O posto é, pois, uma posição situada num dispositivo geral (sistema). Corresponde a um papel fixado comportando ordens, isto é, instruções sobre o que é necessário fazer, quando fazê-lo, e como fazê-lo.

Assim, pode-se referir que os postos de trabalho fazem parte do dia-a-dia de praticamente todos os tipos de atividades (profissionais ou outras) do Ser Humano. Segundo Gomes Filho (2003), um posto de trabalho faz parte de um tradicional sistema de produção e, de um modo geral, está inserido nas empresas (indústria, comércio, serviços...).

Dentro deste conceito encontram-se os postos de trabalho eletrónicos, considerados aqui como sistemas interativos públicos. Neste tipo de equipamentos, os utilizadores realizam a tarefa instruindo o sistema sobre o que fazer. O utilizador pode dar as ordens de várias maneiras, mas na maioria dos casos é feita através da pressão de determinado botão.

Tabela 1. Sistemas Interactivos Agrupados Segundo Áreas Funcionais Área / Tipologias / Produtos/Serviços

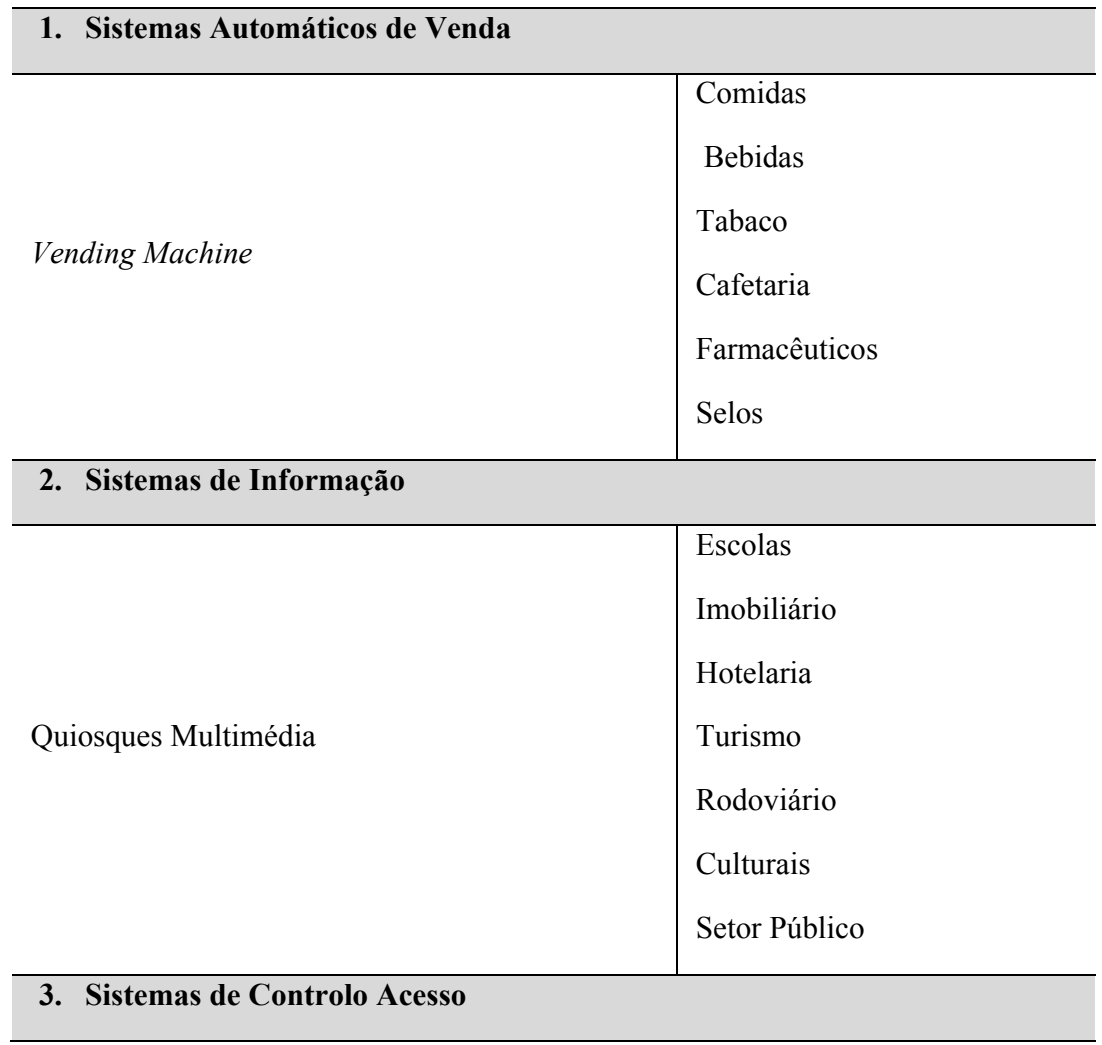




\begin{tabular}{|c|c|}
\hline Controlo Acessos & $\begin{array}{l}\text { Campainhas } \\
\text { Elevadores } \\
\text { Vídeo Porteiro } \\
\text { Obliteradores } \\
\text { Torniquetes } \\
\text { Biométrico }\end{array}$ \\
\hline \multicolumn{2}{|l|}{ Sistemas de Bilhética } \\
\hline Postos de Venda Bilhetes & $\begin{array}{l}\text { Transportes Públicos } \\
\text { Estacionamento }\end{array}$ \\
\hline Bilhética sem Contacto & $\begin{array}{l}\text { Cinemas } \\
\text { Teatros } \\
\text { Exposições } \\
\text { Eventos } \\
\text { Espetáculos }\end{array}$ \\
\hline \multicolumn{2}{|l|}{ 4. Sistemas Bancários } \\
\hline Caixa Automáticas & Serviços Bancários Standard \\
\hline Terminais Eletrónicos & $\begin{array}{l}\text { Serviços Bancários } \\
\text { Abrangentes }\end{array}$ \\
\hline \multicolumn{2}{|l|}{ 5. Sistemas Pagamento Automático } \\
\hline Terminal de Pagamento Automático & $\begin{array}{l}\text { Lojas/Restaurantes } \\
\text { Serviços Diversos }\end{array}$ \\
\hline Caixa Automática Self- Checkout & $\begin{array}{l}\text { Pequenas e Grandes } \\
\text { Superfícies } \\
\text { Lojas de média/grande } \\
\text { dimensão }\end{array}$ \\
\hline
\end{tabular}

Um dos benefícios deste tipo de conceito, que se baseia no fornecimento de uma instrução, é o de sustentar uma ação rápida e eficiente, sendo por isso, adequado principalmente para as ações repetitivas realizadas com objetos múltiplos como é o caso dos sistemas em causa (Preece 2005). 


\subsection{Sistemas Interativos Públicos - Caracterização}

\subsubsection{Sistemas de Venda Automática (Vending)}

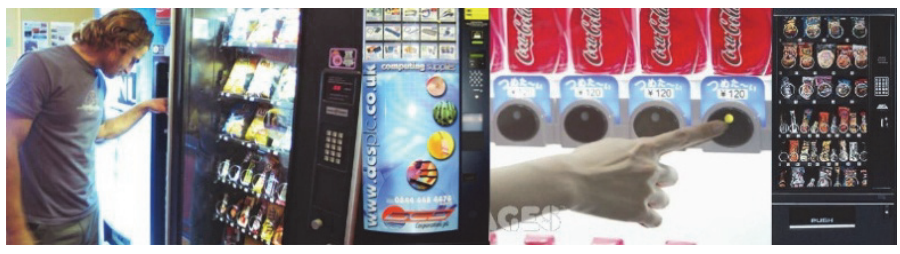

Fig. 1 - Máquinas de Vending.

Os sistemas de venda automática de produtos (Vending Machine) são máquinas que utilizam interfaces de baixa ou média complexidade (Fig. 1). Estes equipamentos localizam-se em pontos de alto fluxo e com visibilidade elevada, sendo os canais de venda de produtos de marcas de alta perceção junto ao seu público-alvo.

Os produtos oferecidos apresentam a caraterística de serem de conveniência, com os quais os consumidores não estão dispostos a gastar muito tempo e esforço para comprá-los (Beisel,1993). São produtos que tentam satisfazer necessidades fisiológicas básicas, a fome e a sede, impulsionando o utilizador para o consumo de alimentos e bebidas e tabaco.

A figura 2 mostra as imagens de duas máquinas diferentes, uma de refrigerantes e outra de vários tipos de snacks.

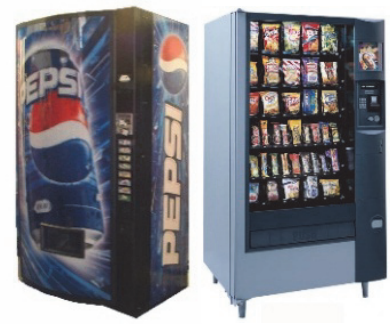

Fig. 2 - Sistemas Venda Automática. (a) Máquina de venda de refrigerantes. (b) Máquina de venda de "snacks"

A primeira, máquina foi projetada de acordo com um modelo bastante simples que se baseia numa só instrução. Há poucos tipos de refrigerantes e cada um está representado por um botão que exibe a marca da bebida. O utilizador apenas pressiona determinado botão e recebe a bebida selecionada. A segunda máquina é mais complexa e apresenta maior número de produtos.

Dado o maior número de opções, esta não pode ser instruída através de um simples toque, é necessário um processo mais complexo, que envolve os seguintes cinco (5) passos:

1. Ler o código do produto,

2. Digitar esse código no painel ao lado,

3. Verificar o preço da opção selecionada,

4. Colocar as moedas,

5. Retirar o produto. 


\subsubsection{Sistemas de Informação}

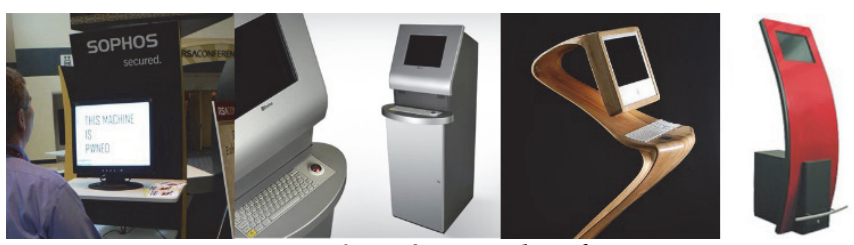

Fig. 3 - Máquinas de Informação.

Os sistemas de informação são postos de trabalho que utilizam um modelo conceptual que se baseia em pesquisa e navegação (Fig. 3). Estes modelos possibilitam ao utilizador explorar e pesquisar informações valendo-se da sua experiência adquirida noutras plataformas informáticas.

Estes equipamentos disponibilizam informação institucional das organizações, dos fabricantes, dos catálogos dos produtos, eventos, marketing e promoção, em que o utilizador procura a informação disponibilizada através de pontos de acesso à Internet.

Neste tipo de sistemas, Quiosques Multimédia, tem grande importância a forma como se estrutura a informação de modo a fornecer suporte a uma navegação efetiva e permitir ao utilizador pesquisar, procurar e encontrar diferentes tipos de informação.

\subsubsection{Sistemas de Acessos}
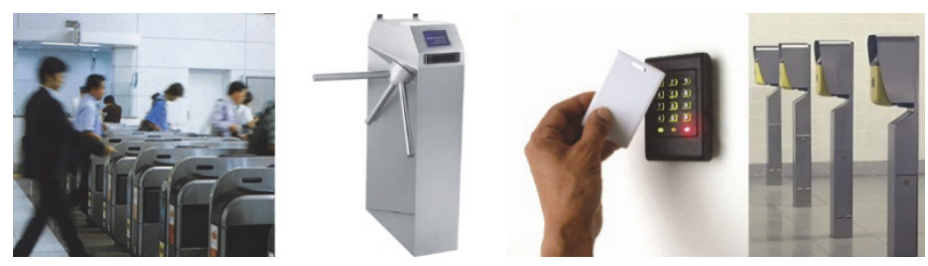

Fig. 4 - Máquinas de Acessos.

O termo controlo de acessos refere-se a máquinas que utilizam interfaces de baixa complexidade e estão relacionados com segurança física, sendo uma referência à prática de permitir o acesso a pessoas autorizadas a uma propriedade, prédio, sala, instalações desportivas e de espetáculo (Fig. 4).

O controlo físico de acessos pode ser obtido através de meios mecânicos como fechaduras e chaves; ou através de outros meios tecnológicos, como sistemas baseados em cartões de acesso de leitura de fita magnética, de códigos de barras, de proximidade, da combinação do leitor e teclado, ou através da introdução de dados biométricos que identificam o utilizador

O sistema é composto por processos de autenticação, autorização e auditoria. A autenticação identifica o utilizador, a autorização determina o que um utilizador autenticado pode fazer, e a auditoria diz o que o utilizador fez. 


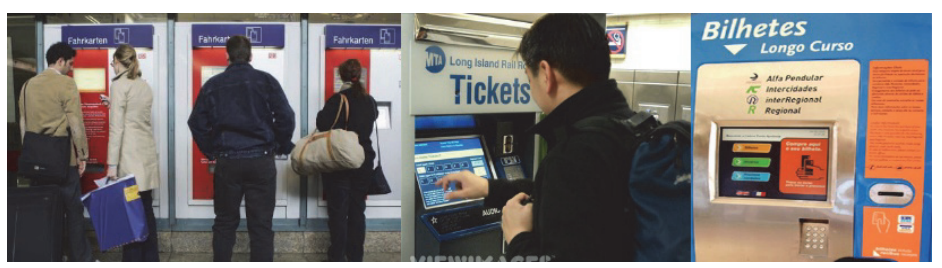

Fig. 5 - Máquinas de Bilhética

Os sistemas de bilhética são postos de trabalho eletrónicos que utilizam interfaces de média complexidade tendo como objetivo a venda de bilhetes para os mais variados fins, entre eles, os transportes rodoviários, ferroviários e fluviais, recintos de exposições, de desporto, culturais como salas de espetáculos, cinemas e teatros (Fig. 5).

O sistema de bilhética tem a caraterística de ser um sistema que está exposto ao grande público que compra, manipula e valida os bilhetes antes de passar as barreiras de controlo de acesso. Dado ser um equipamento manipulado pelo utilizador, o fator ergonómico ganha especial importância de forma a facilitar a sua utilização.

Em geral, estes aparelhos de venda de bilhetes exigem que sejam dadas várias instruções em sequência, por uma ordem que pode ser lógica ou arbitrária, o que pode levar o utilizador menos experiente a cometer erros.

Verifica-se ainda, que as ações necessárias nas diferentes máquinas com a mesma função variam muito de marca para marca, evidenciando pouca preocupação de padronização. Portanto, o conhecimento que o utilizador adquire numa máquina durante a interação, poderá não ser muito útil ao executá-la noutra.

\subsubsection{Sistemas Bancários}

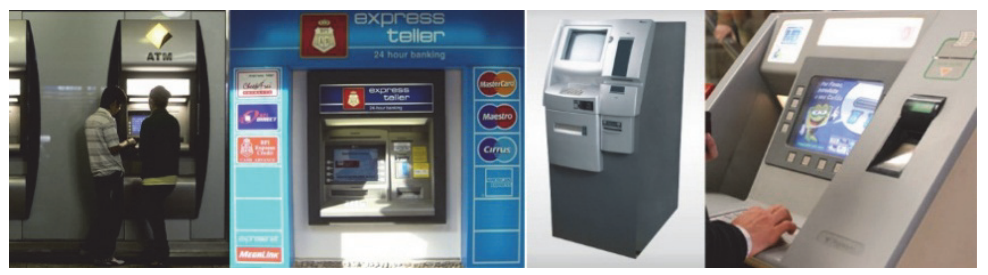

Fig. 6 - Máquinas Bancárias.

Os sistemas bancários são constituídos essencialmente por caixas eletrónicas e terminais eletrónicos (Fig. 6). São postos de trabalho informatizados relativamente complexos, inseridos nos processos de automação bancária e funcionam como uma mini agência.

Disponibiliza serviços à base de auto atendimento, tendo como principal caraterística, a prestação de serviços bancários de modo ininterrupto e a utilização pelo cliente é efetuado através de cartão bancário.

O cliente/utilizador tem acesso pronto e automático às diversas modalidades de serviços prestados pelo banco: levantamento de dinheiro, consultas, transferências de valores entre contas, depósitos, realização de aplicações e investimentos, obtenção de estratos impressos, pagamentos de serviços, de e para outros serviços. 
O utilizador-cliente necessita de alguma experiência para realizar certas tarefas e evita explorar no interface novas funcionalidades dada a responsabilidade que podem acarretar as ações incorretas.

\subsubsection{Sistemas de Pagamento Automático}

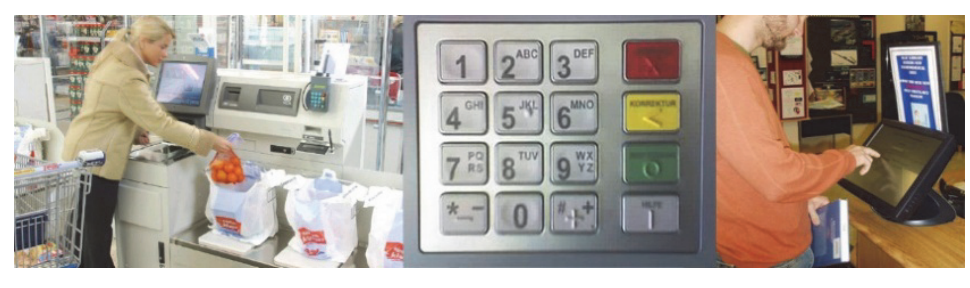

Fig. 7- Máquinas de Pagamento

Relativamente aos sistemas de pagamento automático são produtos que utilizam interfaces de baixa complexidade, como um simples terminal de pagamento automático, que permite realizar pagamentos eletrónicos no ponto de venda mediante a utilização de um cartão bancário (Fig. 7). O utilizador-cliente apenas tem que verificar o valor a pagar e introduzir o código secreto.

Outros produtos de pagamento utilizam interfaces de uso complexo, como as caixas de registo e pagamento self-checkout. Nestes sistemas, o cliente regista todos os produtos e no final efetua o pagamento.

É um sistema complexo que obriga a uma grande quantidade de ações em sequência, sendo necessária por vezes a presença de operadores para assistir os clientes, principalmente durante as primeiras utilizações.

Estes sistemas colmatam os problemas de fluxo, principalmente dos consumidores com pequenas unidades de produtos, e privilegia a rapidez, o controlo da operação e a privacidade. Estes equipamentos estão disponíveis em bombas de gasolina, restaurantes self-service e em grandes superfícies comerciais.

\section{Análise e Discussão dos Resultados}

A análise realizada às seis tipologias reconhece que no espaço urbano público o utilizador encontra sistemas eletrónicos muito diversos (Tabela 2). A análise à complexidade dos sistemas foi realizada tendo como base a utilização de cada equipamento numa ação standard (A/S) (ou de "uso principal do produto" (Gomes Filho, 2006)). 
Tabela 2. Grau de Complexidade dos Sistemas

\begin{tabular}{|c|c|c|c|c|c|}
\hline Tipologias & Produto & $\begin{array}{c}\text { Baixa } \\
\text { (Simples } \\
\text { de uso) } \\
\mathbf{1 - 4}\end{array}$ & $\begin{array}{c}\text { Média } \\
\text { (Sistémico } \\
\text { de uso) } \\
\text { 5-10 }\end{array}$ & $\begin{array}{c}\text { Alta } \\
\text { (Sistémico } \\
\text { de uso e } \\
\text { muito } \\
\text { tecnol.o) } \\
\mathbf{1 0 ~ ( + ) ~}\end{array}$ & $\mathbf{N}^{0}$ Ações \\
\hline $\begin{array}{l}\text { 1.Sistemas de Venda Automáticos } \\
\text { A/S: Adquirir um snack. }\end{array}$ & $\begin{array}{l}\text { Vending } \\
\text { Machine }\end{array}$ & & & & $2-8$ \\
\hline $\begin{array}{l}\text { 2.Sistemas de Informação } \\
\text { A/S: Obter informação turística }\end{array}$ & $\begin{array}{l}\text { Quiosques } \\
\text { Multimédia }\end{array}$ & & & & $2-8$ \\
\hline $\begin{array}{l}\text { 3.Sistemas Controlo de Acessos } \\
\text { A/S: Entrar num banco }\end{array}$ & $\begin{array}{c}\text { Controlo de } \\
\text { Acessos }\end{array}$ & & & & $1-3$ \\
\hline 4.Sistemas de Bilhética & $\begin{array}{c}\text { Bilhética s/ } \\
\text { contacto }\end{array}$ & & & & $5-8$ \\
\hline A/S: Comprar um bilhete & $\begin{array}{c}\text { Postos E. } \\
\text { Venda Bilh. }\end{array}$ & & & & $5-8$ \\
\hline 5.Sistemas Bancários & $\begin{array}{c}\text { Terminais } \\
\text { Eletrónicos }\end{array}$ & & & & $5-8$ \\
\hline A/S: Levantar dinheiro & $\begin{array}{c}\text { Caixa } \\
\text { Automático }\end{array}$ & & & & $5-15$ \\
\hline \multirow{2}{*}{$\begin{array}{l}\text { 6.Sistemas Pagamento Automático } \\
\text { A/S: Pagamento de um produto/serviço }\end{array}$} & $\begin{array}{c}\text { Terminal } \\
\text { (TPA) }\end{array}$ & & & & $2-4$ \\
\hline & $\begin{array}{c}\text { Caixa Self- } \\
\text { Checkout }\end{array}$ & & & & $12-20$ \\
\hline
\end{tabular}

Assim, tendo como base para a análise comparativa uma ação standard definiu-se para o caso dos sistemas:

- Venda Automático - a ação "Comprar um produto alimentar (ex. snack) ";

- Informação - a ação "Obter informação turística (ex. uma cidade) ";

- Controlo de Acessos - a ação "Entrar num espaço público restrito (ex. Banco)",

- Bilhética - a ação "Comprar um bilhete";

- Bancários - a ação "Levantar dinheiro",

- Pagamento Automático - a ação "Pagamento de um Produto/Serviço".

Conclui-se pela análise realizada, que o grau de complexidade dos sistemas é muito diverso, determinado por um conjunto de ações muito distintas e em diferente número. 
Assim, relativamente aos sistemas de Venda Automáticos podem apresentar um grau de complexidade baixo a médio porque a inter-relação varia entre um (2) a cinco (8) ações.

Nos sistemas de Informação, em que a interação é baseada na dinâmica pesquisa-navegação, as ações variam entre dois (2) a oito (8) ações. Caso o indivíduo necessite de mais informação, as oito ações serão ultrapassadas.

Nos sistemas de Controlo de Acessos, verifica-se um baixo grau de complexidade dado que o indivíduo apenas tem que interagir com o dispositivo entre uma (1) a três vezes (3). Ou passar um cartão, ou passar um cartão e digitar um código, ou estas duas e carregar num botão.

Quanto aos sistemas de Bilhética, o grau de complexidade é médio. Nos dois sistemas de bilhética analisados o número de ações varia entre cinco (5) e oito (8).

Relativamente aos sistemas Bancários, verifica-se um grau médio a alto de complexidade dado que o indivíduo nos Terminais Eletrónicos tem que interagir entre cinco (5) a oito (8) vezes com o sistema enquanto na Caixa Automático a variação pode ser maior, entre as cinco (5) e as quinze (15) ações.

Quanto aos sistemas de Pagamento Automático, verifica-se um baixo e um alto grau de complexidade dado que o utilizador no TPA só tem que realizar entre dois (2) a quatro (4). Por outro lado, nas Caixas Automáticas Self-Checkout o utilizador tem que realizar no mínimo doze (12) ações que, para o mesmo produto, pode chegar até vinte (20) ações. Nestas caixas, o utilizador tem que efetuar primeiro o registo do produto antes de efetuar o pagamento.

Tomando como referência a ação standard de cada sistema e por análise comparativa chegou-se aos valores muito diferenciados (tabela 3 ).

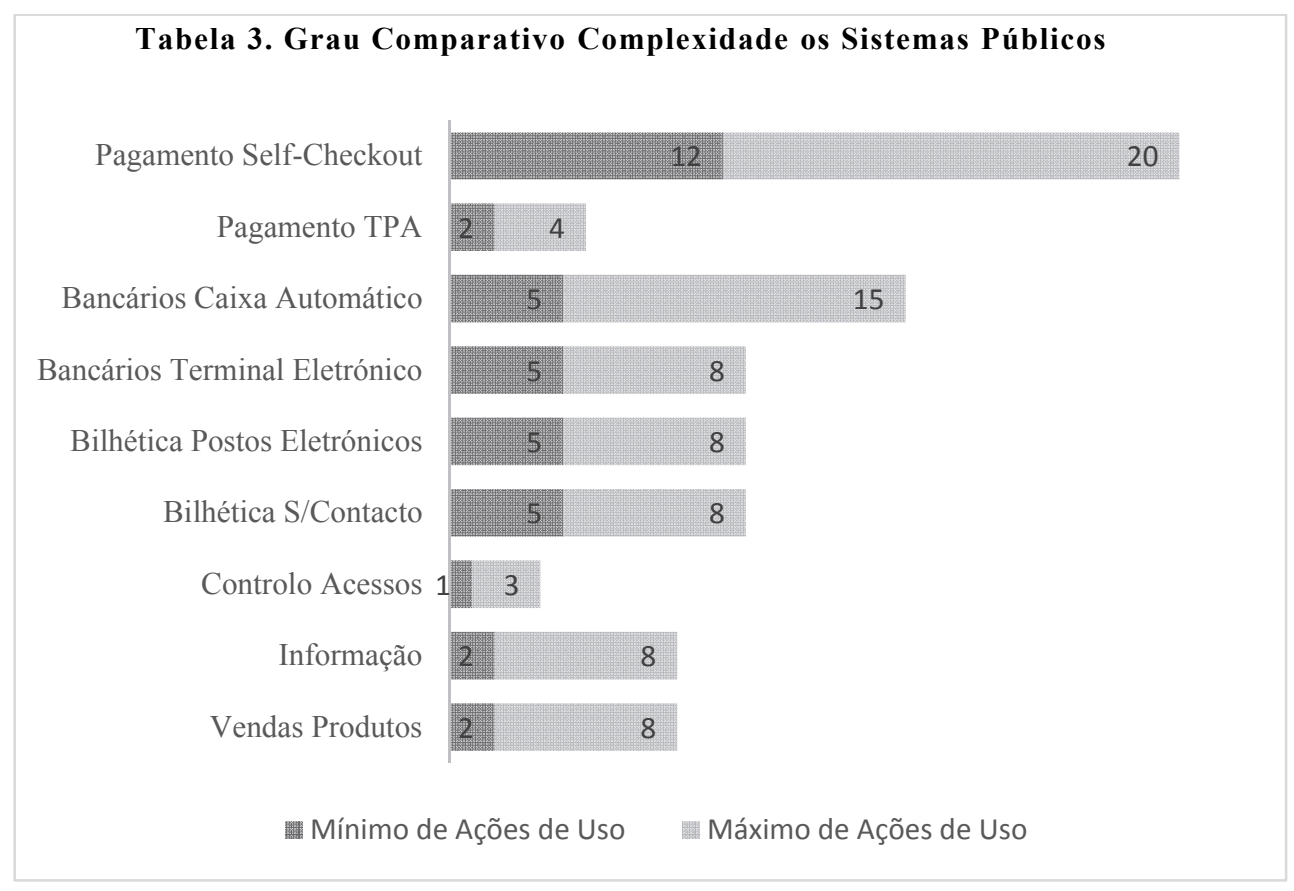

Dos resultados apresentados verifica-se que o sistema de Pagamento Self-Checkout é o que apresenta o número de ações mais elevado, entre 12 a 20 ações. Outro dos sistemas que merece a nosso atenção é o 
Bancário de Caixa Automático, o qual apresenta igualmente um número de ações que pode chegar às quinze (15). Relativamente ao sistema de controlo de acessos, é o sistema que apresenta os valores mais baixos entre 1 a 3 .

Assim, no contexto do acesso aos sistemas eletrónicos urbanos públicos analisados, o sistema de Pagamento Self-Checkout constitui um problema especial para o Design. O equipamento é de uso sistémico e altamente tecnológico que sob condições de uso normal, deveria simplificar o sector do retalho no fluxo junto ao Checkout e facilitar o trabalho do utilizador aumentando a rapidez e a eficiência durante $\mathrm{o}$ ato de registo e pagamento dos produtos.

Por um lado, são vários os fatores psicológicos que interferem nesse delicado equilíbrio de controlo do sistema:

- Curiosidade

- Desafio da dificuldade

- Tolerância à frustração

- Tolerância ao erro

Por outro, quanto maior for o número de controlos, maior é a complexidade da perceção dos sistemas, obrigando o utilizador a aprender mais sobre a tarefa a desempenhar.

Para fazer com que algo pareça fácil de usar, talvez o Design tenha que minimizar o número de controlos por forma a igualar ao número de funções (Norman, 2006).

\section{Modelos de Análise}

Para explanar a forma como o designer vai ter que intervir, na segunda parte deste estudo debruçámo-nos sobre a noção de Modelo e Análise como forma de definir um esquema orientador da conceção teórica subsequente e a qual deve identificar os aspetos que intervêm no Design de Interação e na relação utilizador-sistema.

Primeiramente refletimos sobre os conceitos associados aos modelos teóricos, e verificámos na literatura a noção de "Modelo Mental e de "Modelo Conceptual" do ponto de vista do utilizador e do designer.

Seguidamente, e com base na análise global propusemos um Modelo de Análise onde se determina as relações entre os conceitos, as suas dimensões e indicadores, e onde se organiza de forma lógica e integradora as diversas variáveis e a dinâmica do assunto tratado (Sousa e Baptista, 2011).

\subsection{Modelo Mental e Modelo Conceptual}

Um modelo mental é uma representação de um objeto ou de um processo, sendo estruturalmente análogo aquilo que ele representa (Johnson-Laird, 1983). Embora seja incompleto e não represente diretamente a realidade, habilita o indivíduo que o possui, de fazer previsões ou de dar explicações (Kleer e Brown, 1981). Um modelo mental pode ser adquirido através da transmissão cultural, de instrução e das interações com outras pessoas e com o mundo (Borges, 1999).

Os modelos mentais são representações dinâmicas e produtivas que podem ser manipuladas mentalmente para proporcionar explicações causais de fenómenos físicos e para realizar previsões sobre o estado de coisas no mundo físico. 
Muitos modelos são criados no momento da resolução de um problema específico, devido às solicitações dessa situação. No entanto, é possível que alguns modelos mentais, ou partes deles, mostraram utilidade no passado, sejam armazenados como estruturas separadas e recuperadas da memória de longo prazo quando necessário.

O conceito de Modelo Mental tem sido utilizado por diferentes estudos e de diferentes formas JohnsonLaird (1983), tendo tido início na psicologia e do qual a ergonomia faz várias leituras.

Para Helander (1997) é a expectativa que um utilizador tem em relação ao comportamento do computador.

Segundo Sutcliffe (1995), os modelos mentais podem ser divididos em modelos físicos e em modelos conceptuais.

- Os Modelos Físicos descrevem o relacionamento de objetos no mundo real em termos de distribuição espacial de eventos num dado período. Podem ser visualizados, especialmente se o problema envolve raciocínio espacial.

- Os Modelos Conceptuais são expressões linguísticas superficiais numa linguagem interna que, embora baseada na linguística, representa uma abstração futura. Modelos conceituais são uma espécie de linguagem mental interna que representa valores reais sobre objetos e as suas relações. A forma dos modelos mentais difere de pessoa para pessoa e depende de estilos cognitivos pessoais.

Preece et al (1994), defende que quando se interage com qualquer coisa, que pode ser o ambiente, outra pessoa ou artefato tecnológico, criam-se modelos mentais internos ao utilizador. E quando executados ou repetidos do início ao fim, os modelos "propiciam as bases a partir das quais se podem predizer ou explicar as nossas interações".

Moraes e Mont'Alvão (2000), destacam que o termo algumas vezes refere-se ao modelo que o utilizador tem do sistema, outras ao modelo que o projetista tem do sistema, e outras ainda, ao modelo que o projetista ou o sistema tem do utilizador.

Para Senge (1996), modelos mentais são feitos de premissas profundamente enraizadas, generalizações ou mesmo figuras ou imagens que influenciam como entendemos o mundo e como agimos.

Em comum a todas as definições está a ideia de que possuímos mapas cognitivos, a partir dos quais interpretamos os ambientes complexos e agimos sobre eles.

Assim, os autores atrás referidos preferem usar o termo modelo mental como o modelo que o utilizador tem do sistema. Então, modelo mental do utilizador "compreende o modelo do sistema, formado pelo utilizador, através de experiências e interações com o sistema e a partir da imagem do sistema" (Moraes, 2000).

Para Norman (2002), o modelo mental é o modelo conceptual do utilizador sobre a maneira particular como um objeto funciona, como os eventos acontecem ou como as pessoas se comportam. "Esses modelos são essenciais pois dão ao indivíduo uma visão sobre o mundo, sobre as suas próprias capacidades e sobre as tarefas que lhe são solicitadas realizar. Os modelos mentais possuem um poder de explicação e de previsão para o entendimento dessas relações - ajudam a entender as nossas experiências, prever as reações das nossas ações e manipular ocorrências inesperadas". 
Para Booth (1992), esses modelos "são sempre construídos de evidências fragmentadas, com um entendimento pobre do que está a acontecer, e com um tipo de psicologia ingénua que procura causas, mecanismos e relações mesmo quando elas não existem", resultando na tendência que o ser humano tem de dar explicações para as coisas.

Em relação aos modelos mentais, Norman (1983) refere que é necessário considerar quatro elementos diferentes:

- O sistema alvo

- O modelo conceptual do sistema alvo

- O modelo mental do sistema alvo construído pela pessoa

- O modelo do cientista deste modelo mental

O sistema que a pessoa está a aprender ou a usar é, por definição, o sistema alvo. Um modelo conceptual é inventado por professores, projetistas, cientistas e engenheiros para proporcionar uma representação apropriada do sistema alvo, no sentido de ser preciso, consistente e completo.

Os modelos mentais são modelos em evolução, pois através da interação com o sistema, o utilizador altera o seu modelo mental no sentido de obter um resultado viável. Este modelo em evolução privilegia a funcionalidade em detrimento da precisão técnica.

Os modelos mentais são limitados pelo conhecimento técnico do utilizador, suas anteriores experiências com sistemas similares e pela estrutura do sistema humano de processamento de informações.

Norman (ibidem) concluiu que a compreensão que as pessoas têm sobre os dispositivos com os quais interagem é fraca, imprecisa e inconsistente. Os modelos contêm apenas descrições parciais das operações e uma grande área de incerteza.

Norman (ibidem) chegou à seguinte generalização sobre os modelos mentais:

1. São incompletos.

2. A destreza do utilizador em manipular os modelos é muito limitada.

3. São instáveis: o utilizador esquece detalhes do sistema, especialmente quando esses detalhes não são usados durante um certo tempo.

4. Não possuem limites rígidos: dispositivos e operações similares ocasionam confusão.

5. Não são científicos: o utilizador tem comportamentos supersticiosos mesmo sabendo que estes não resultam.

6. São parcimoniosos: O utilizador está disposto a realizar um esforço físico suplementar em troca de um modelo mental menos complexo.

As ciências cognitivas podem ajudar a entender as estruturas incompletas, indistintas e confusas que o utilizador tem sobre os produtos tecnológicos. Os designers têm a obrigação de desenvolver sistemas que ajudem o utilizador a conceber modelos mentais adequados à sua interação com o sistema. Ter em consideração o conhecimento do utilizador em termos de modelos mentais pode ajudar o designer a desenvolver interfaces apropriadas. 
Norman (2002) afirma que o modelo conceptual permite simular mentalmente a manipulação de um dispositivo. Qualquer artefacto será mais simples de utilizar se tiver um bom modelo conceptual. Uma parte fundamental no desenvolvimento de um modelo consiste em determinar se as ideias criadas a respeito de como o sistema se deve parecer e se comportar, serão entendidas pelos utilizadores da maneira que se pretende.

Com base nos princípios apresentados, o designer deve assim construir um modelo conceptual para o artefacto que seja adequado ao uso.

Norman (ibidem) distingue três componentes associados ao artefacto: o Modelo do Designer, o Modelo do Utilizador e a Imagem do Sistema (fig.8). Os modelos do designer e do utilizador são modelos mentais. As pessoas formam modelos mentais de si próprias, das coisas e das pessoas com as quais interagem.

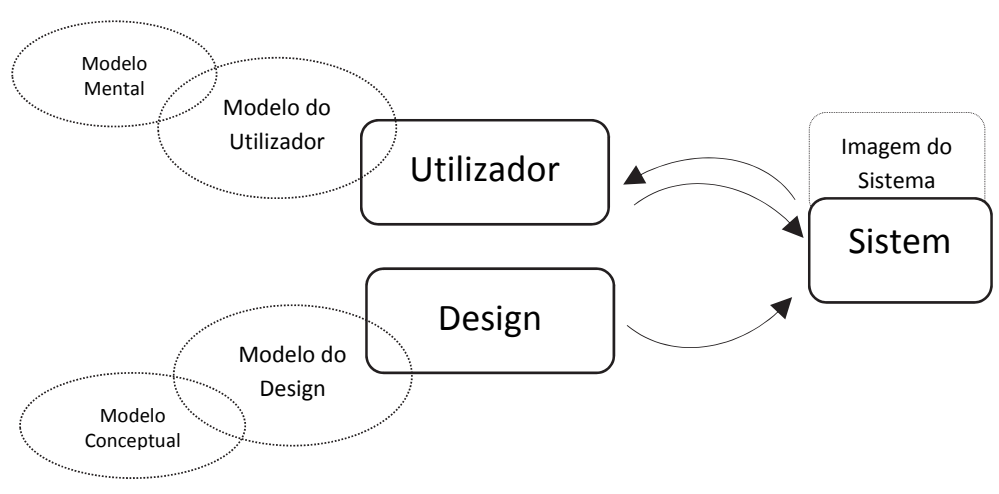

Fig. 8 Adaptado segundo o Modelo Conceptual de Norman (2002)

Esses modelos terão o poder de previsão e explicação, necessários para a condução da interação. Assim,

- O Modelo do Utilizador é o modelo mental que o utilizador desenvolve na interação com o sistema.

- O Modelo do Designer é o conceito que o designer tem sobre como o sistema deve trabalhar.

- A Imagem do Sistema resulta da estrutura visível do dispositivo, da sua aparência física, da sua forma de operar, de como responde..

Seria ideal, que o modelo do designer e do utilizador, coincidissem. O designer espera que o modelo de design seja idêntico ao do utilizador. Mas o utilizador não tem acesso direto ao modelo do design para compreender o funcionamento do dispositivo, ele tem que formar o seu próprio modelo mental através da imagem do sistema durante o uso.

Para tal, o designer deve assegurar que a imagem do sistema deixe o modelo de design claro, consistente, coerente, completo e sem contradições de forma a não haver dificuldades na sua utilização. 


\subsection{Modelo de Análise}

Um modelo de análise é neste caso uma representação esquemática da realidade. O modelo de análise seguinte apresenta o esquema teórico representativo das dinâmicas que se estabelecem no Processo de Design de Interação Utilizador-Sistema e identifica ainda as variáveis e as relações que se estabelecem entre elas (Fig. 9).

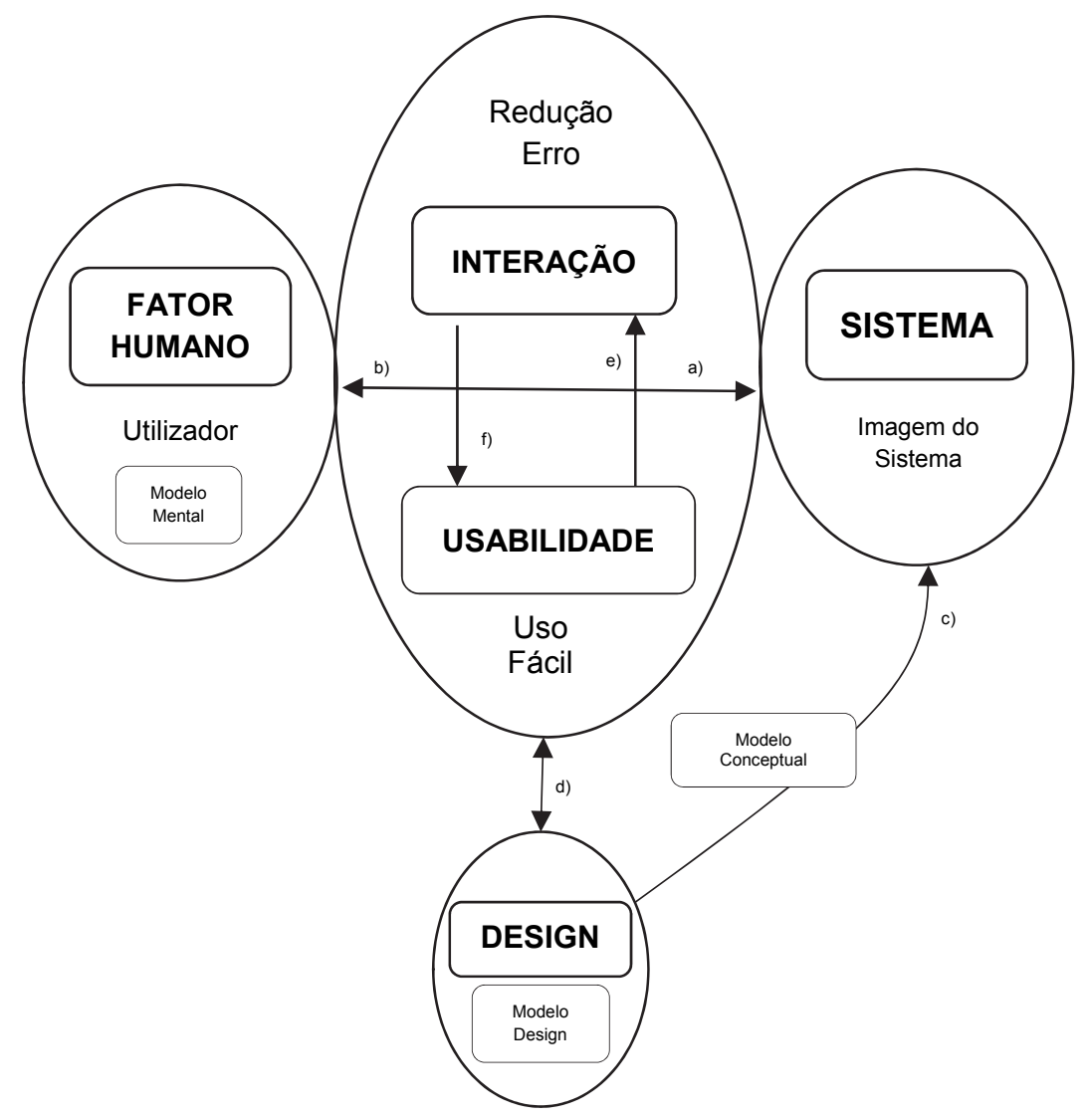

Fig. 9 - Modelo de Análise da Interação Utilizador-Sistema no Processo de Design

A partir da leitura do modelo analítico podemos afirmar que, para se estudar as dinâmicas da interação utilizador-sistema, existem quatro dimensões fundamentais: o Fator Humano, o Sistema, a Interação/Usabilidade e o Design.

Dentro das dimensões principais temos primeiramente a dimensão Fator Humano. Esta dimensão é o conjunto formado pelos utilizadores que vão interagir com o sistema e que vão adquirir experiencia pelo treino e instruções. O modelo mental a ele associado traduz como o utilizador pensa que o sistema funciona. Ele é influenciado pela interação com o sistema, pelas suas experiências anteriores e pela leitura de manuais de funcionamento. O utilizador é uma das variáveis independentes da análise dado ter caraterísticas intrínsecas ao fator humano como: sexo, idade, formação, experiência, social, cultural, hábitos, e linguística.

Na segunda dimensão temos o Sistema, o qual é a estrutura do dispositivo construído pela interface com as funções. A esta dimensão temos associado a Imagem do Sistema, onde o utilizador irá adquirir informação para formar o seu modelo de utilizador. Isso processasse através da interpretação das ações 
percebidas e da estrutura visível do sistema. O sistema assume aqui outra das variáveis da análise dado ter caraterísticas diferentes inerentes ao equipamento: dipositivo eletrónico, física da máquina (dimensão, cor, forma, corpo (sustentáculo do sistema), interface, hardware, e software) e funções (número quantidade, complexidade, variedade).

Noutra dimensão temos a Interação e a Usabilidade. A Interação tem como objetivo reduzir o erro durante a utilização do sistema. Para isso, analisa a relação psíquica do utilizador durante o uso, as suas expectativas, as ações, e os aspetos relacionados com conforto e complexidade. Para além disso, identifica as necessidades e problemas traduzidos pelas variáveis: eficácia, eficiência, segurança / utilidade, facilidade de aprender e de lembrar. Diretamente relacionado com a Interação está a Usabilidade. A Usabilidade diz respeito ao estudo da forma como o sistema é usado. Para isso, analisa e define as caraterísticas das interfaces, os atributos e os requisitos de usabilidade, e determina as linhas guia.

A outra dimensão considerada no modelo de análise global é o Design. O Design é neste contexto desenvolvido com utilizadores e para os utilizadores. O projeto é centrado no utilizador (grupo piloto) e analisa as experiências, as necessidades e a reação ao interface. Depois é definido o modelo de design que é um modelo conceptual do sistema. Dentro desta dimensão estão incluídos diversos conceitos que são fundamentais para a definição de todo o processo como por exemplo o público-alvo. Esse público pode ser potencial, indireto/ocasional e o público que altera a decisão de compra por ser afetado pela introdução do sistema.

Relativamente às interligações entre as dimensões mencionadas, pressupõe-se que os utilizadores que têm um modelo mental de como o sistema funciona, ao interagir com este, vão observar a imagem do sistema, apreender e controlar $(a)$.

O sistema, por sua vez, apresenta um modelo conceptual de utilização que deve ser compreendido pelos utilizadores $(b)$.

Esse modelo conceptual é definido pelo design (c), determinado pelo modelo mental do designer, ou seja, de como ele considera que o utilizador vai interagir com o sistema, e pela pesquisa por ele realizada (d). É aplicada ao estudo da usabilidade do sistema com o objetivo de alcançar um bom nível de facilidade no uso e é aplicada no estudo da interação com o objetivo de reduzir o erro e poder fazer melhoramentos contínuos no modelo conceptual.

Por último, a usabilidade que define as linhas guia segundo os requisitos de usabilidade tem influência na interação (e). Esta dimensão analisa as ações e a complexidade do sistema e tem como referência um guião para a usabilidade. Por sua vez, ao determinar o grau de interação do sistema determina o seu nível de usabilidade $(f)$.

Do ponto de vista do designer, o grande contributo para o projeto de investigação do modelo de análise descrito é proporcionar um enfoque teórico no estudo a realizar posteriormente.

\section{Conclusões}

Este trabalho procurou apresentar a problemática da relação entre o utilizador e os sistemas eletrónicos públicos do ponto de vista do design de interação. Partindo de uma abordagem ao conceito de design de interação, passando pela análise dos sistemas eletrónicos públicos, identificou-se a existência de seis tipologias, as quais, segundo a análise do seu grau de complexidade, permitiu aferir a diversidade de equipamentos públicos com que o utilizador tem que interagir no dia-a-dia e aqueles que requerem maior aprendizagem. 
Este trabalho procurou ainda apresentar os conceitos envolvidos com a análise das variáveis Fator Humano - Sistema, efetuando-se por isso, um modelo de análise que permitiu definir as dimensões, conceitos e variáveis que contribuem para o design de sistemas.

Neste contexto, designa-se por Design de Interfaces, a área do design que associa o design de produto ao design gráfico, nomeadamente equipamentos que integrem informações textuais, simbólicas, icónicas, mais a identificação de funções operacionais. Por outro lado, designa-se por Design de Interação todos os produtos tridimensionais com os quais o utilizador tem uma experiência de manipulação, e a forma como ele lida com as estruturas de ação que definem os procedimentos de uso.

Os modelos mentais que o utilizador desenvolve na interação com os vários sistemas, têm que ser simples e de rápida aprendizagem.

Por um lado, ao designer apresentam-se questões que têm a ver com a ideia que ele tem sobre a forma como o sistema deve funcionar e vai ser percecionado pelo utilizador. Por outro, a perceção efetiva que o utilizador tem durante o uso.

Para isso, o designer deve assegurar que a imagem do sistema deixe o modelo de design simples, de acessível compreensão e de fácil aprendizagem para que o utilizador não acabe com um perceção inadequada.

A questão da e interação e usabilidade dos equipamentos urbanos, compostos pela integração de várias equipamentos eletrónicos é pouco divulgada, fazendo com que seja necessária mais estudos sobre o assunto. Esta questão torna-se ainda mais premente, dado que a utilização destes equipamentos está em plena expansão.

Um design apropriado pode facilitar a aprendizagem e compreensão como exigir menor controlo e precisão por parte do utilizador. Pode ainda reduzir a incidência e a gravidade de erros ao eliminar as suas causas e melhorar a execução das tarefas diárias.

\section{Referencias}

ABRAHÃO, J., et al (2013). Ergonomia e Usabilidade. 1ª Edição. São Paulo: Blucher.

ALDAWOOD, S. et al. (2015). "Collaborative Tangible Interface (CoTI) for Complex Decision Support Systems". MARCUS, A. (Ed.). Em: Design, User Experience, and Usability: Design Discourse. Fourth International Conference, DUXU 2015, Los Angeles, CA., U.S.A. Springer International Publishing, Switzerland. PP. 415-424.

BANCO DE PORTUGAL. (2014). "Terminais de Pagamento e Caixas Automáticos”. In: Cadernos do Banco de Portugal, Edição Departamento de Sistemas de Pagamentos, Serviço de Edições e Publicações, Lisboa

$<$ Http://www.bportugal.pt/pt-

PT/PublicacoeseIntervencoes/Banco/CadernosdoBanco/Biblioteca\%20de\%20Tumbnails/Terminais\%20de\%20Pagam ento\%20e\%20Caixas\%20Autom\%C3\%A1ticos.pdf> [consulta: 29 Março 2016]

BONSIEPE, G. (1992). Teoria e Prática do Design Industrial - Elementos para um Manual Crítico. Lisboa : Centro Português de Design.

BOOTH, P. (2014). An Introduction to Human-Computer Interaction (Psychology Revivals). London Taylor and Francis. 
BORGES, T. (1999). "Como Evoluem os Modelos Mentais, Investigações em Ensino”, Artigo. In: Revista Ensaio Pesquisa em Educação em Ciências. Vol. 1, nº 1, Setembro. UFMG.

$<$ Http://www.portal.fae.ufmg.br/seer/index.php/ensaio/article/view/15/41> [consulta: 25 Março 2016]

BÜRDEK, B. (2006). História, Teoria e Prática do Design de Produtos. São Paulo: Editora Edgard Blücher, Terphane Ltda.

DIX, A. et al (2004). Human-Computer Interaction. Third edition. Pearson/Prentice-Hall. New York.

FALZON, P. (org) (2007). Ergonomia. Edgard Blucher. São Paulo.

FERNANDES, F. et al, (2015). Do Ensaio à Investigação - Textos Breves Sobre a Investigação, Bernabé Hernandis, Carmen Lloret e Francisco Sanmartín (Editores), Oficina de Acción Internacional - Universidade Politécnica de Valência Edições ESAD.cr/IPL, Leiria.

GOMES FILHO, J. (2003). Ergonomia do Objeto - Sistema Técnico de Leitura Ergonómica. Escrituras Editora. São Paulo.

HELANDER, M., LANDAUER, T., PRABHU, P. (1997). Handbook of Human - Computer Interaction. NorthHolland: Elsevier.

JOHNSON-LAIRD, P. (1983). Mental Models: Towards a cognitive science of language, inference and consciousness. MA: Harvard University Press. Cambridge.

KLEER, J. e BROWN, J. S. (1983). Pressupostos e ambiguidades em modelos mecanicistas mentais. In: Modelos Mentais, Gentner, G. e Collins, A.

KRIPPENDORFF, K. (2000). Design Centrado no Usuário: Uma Necessidade Cultural. Estudos em Design, Rio de Janeiro, v. 8, n. 3, p.87-88, Set. - Dez.

MORAES, A. MONT’ALVÃO, C. (2000). Ergonomia, Conceitos e Aplicações. 2AB. Rio de Janeiro.

MORAES, A., FRISONI, B. (2001). Ergodesign: Produtos e Processos. Rio de Janeiro: 2AB.

NORMAN, D. (1993). Things That Make Us Smart. Reading. MA: Addison-Welley.

NORMAN, D. (2002). O Design do Dia a Dia. Ed. ROCCO Ltd., Rio de Janeiro.

PREECE, J. et al (2005). Human-Computer Interaction. Harlow, Addison-Wesley. England.

SENGE, P. (1996). Closing the Feedback Loop between Matter and Mind. Dialog On Leadership, Entrevista: Maio 1996. MIT Center For Organizational Learning, Claus Otto Scharmer.

<Http://www.iwp.jku.at/born/mpwfst/02/www.dialogonleadership.org/Sengex1996.html> [consulta: 12 julho 2015]

SOUSA, J., BAPTISTA, C. (2011). Como Fazer Investigação, Dissertações, Teses e Relatórios - Segundo Bolonha. Edições Pactor, Grupo LIDEL, Lisboa.

SUTCLIFFE, A. (1995). Human - Computer Interface Design. G. Hampshire, Macmillan. Londres. 